\title{
Reconstructing the late Ediacaran sulfur cycle using new data from South China
}

\author{
ZHEYU TIAN ${ }^{1}$, YING ZHOU ${ }^{1}$, BENJAMIN J. W. MILLS ${ }^{2}$, \\ MAOYAN ZHU ${ }^{3}$, MIAO LU ${ }^{3}, \mathrm{CHAO} \mathrm{LI}^{4}$, WEI SHI ${ }^{4}$ AND \\ GRAHAM A SHIELDS ${ }^{1}$ \\ ${ }^{1}$ University College London \\ ${ }^{2}$ School of Earth and Environment, University of Leeds \\ ${ }^{3}$ Nanjing Institute of Geology and Palaeontology \\ ${ }^{4}$ China University of Geosciences \\ Presenting Author: z.tian.17@ucl.ac.uk
}

The late Ediacaran Period (c. 580-538 Ma) was an important interval that witnessed dramatic climatic change, biological innovations, such as the first appearance of animal fossils $(\sim 575$ Ma), trace fossils (c. $\sim 565 \mathrm{Ma}$ ) and biomineralization (c. $\sim 550$ $\mathrm{Ma})$, the most extreme negative carbon isotope excursion (DOUNCE / Shuram Excursion) and oxygenation of the deep ocean $[1,2]$. South China has a complete stratigraphic succession of the late Ediacaran Period, making it an ideal place to investigate the linkage between such biological and environmental events.

In this study, we carried out a carbonate-associated sulfate (CAS) sulfur isotope study of the Doushantuo Formation at Lianghong, Sishang-Majiawan, and Qinglinkou sections in South China. CAS has long been used as a powerful proxy to recover the paleo-seawater sulfate sulfur isotope composition $\left(\delta^{34} \mathrm{~S}_{\mathrm{sw}}\right)$ as it occurs more widely and in less restricted marine environments than alternative minerals.

For our study, we developed existing CAS methods to produce an improved, high fidelity $\mathrm{S}$ isotope record that could be compared with published data from South China and around the world. Stable isotope and elemental data indicate that these three successions are relatively well preserved and, by correlation, confirm that the Ediacaran Period experienced episodic redox oscillations throughout the Ediacaran-Cambrian transition. Here we present biogeochemical and conceptual models to explain trends in seawater sulfate sulfur isotope composition and illuminate their connection to regional-to-global ocean redox variability and biological evolution.

[1] MCFADDEN, K. A., et al. (2008). Proc Natl Acad Sci U S A 105, 3197-202.

[2] Wood R, et al. (2019). Nature ecology \& evolution 3(4): 528-538. 